\title{
Inhibition of Nox1 induces apoptosis by attenuating the AKT signaling pathway in oral squamous cell carcinoma cell lines
}

\author{
KUNIHIRO ITO $^{1,2}$, AKINOBU OTA ${ }^{2}$, TAKAYUKI ONO ${ }^{1}$, TOSHIKI NAKAOKA ${ }^{1}$, MD. WAHIDUZZAMAN ${ }^{2}$, \\ SIVASUNDARAM KARNAN $^{2}$, HIROYUKI KONISHI ${ }^{2}$, AKIFUMI FURUHASHI ${ }^{1}$, TOMIO HAYASHI ${ }^{1}$, \\ YOICHI YAMADA $^{1}$, YOSHITAKA HOSOKAWA ${ }^{2}$ and YOSHIAKI KAZAOKA ${ }^{1}$ \\ ${ }^{1}$ Department of Oral and Maxillofacial Surgery, Aichi Medical University Hospital, Aichi 480-1195; \\ ${ }^{2}$ Department of Biochemistry, Aichi Medical University School of Medicine, Aichi 480-1195, Japan
}

Received April 7, 2016; Accepted June 8, 2016

DOI: $10.3892 /$ or.2016.5068

\begin{abstract}
NADPH oxidases, also known as the Nox family, are major sources of reactive oxygen species generation that regulate redox-sensitive signaling pathways. Recent studies have implicated the Nox family in cancer development and progression. However, the involvement of its members in the development of oral squamous cell carcinoma (OSCC) remains to be elucidated. To clarify this issue, we first analyzed mRNA expression of Nox/Duox family members (Nox1, Nox2, Nox3, Nox4, Nox 5, Duoxl and Duox2) in five OSCC cell lines. Noxl and Nox4 mRNAs were highly expressed in four OSCC cell lines. Western blot analysis revealed that the protein expression level of Nox1 was higher than that of Nox4 in the OSCC cell lines. In addition, knockdown of Nox1, but not Nox4, significantly suppressed cell viability and induced apoptosis in the HSC-2 and HSC-3 cells. We also found that a specific AKT inhibitor, perifosine, dose-dependently suppressed OSCC cell growth. Notably, Noxl knockdown significantly attenuated the phosphorylation level of AKT. Furthermore, both Noxl knockdown and perifosine treatment markedly enhanced the cisplatin-induced cytotoxic effect. Taken together, our results
\end{abstract}

Correspondence to: Dr Akinobu Ota, Department of Biochemistry, Aichi Medical University School of Medicine, Building 2, Room 362, 1-1 Yazakokarimata, Nagakute, Aichi 480-1195, Japan

E-mail: aota@aichi-med-u.ac.jp

${ }^{*}$ Contributed equally

Abbreviations: AxV, Annexin V; CDDP, cisplatin; DCFH-DA, 2',7'-dichlorodihydrofluorescein diacetate; DPI, diphenyleneiodonium; HNSCC, head and neck squamous cell carcinoma; NAC, $\mathrm{N}$-acetylcysteine; Nox, NADPH oxidase; OSCC, oral squamous cell carcinoma; PI3K, phosphatidylinositol 3-kinase; PI, propidium iodide; PIK3CA, phosphatidylinositol-4,5-bisphosphate 3-kinase, catalytic subunit $\alpha$; PDTC, pyrrolidine dithiocarbamate; ROS, reactive oxygen species

Key words: apoptosis, NADPH oxidase, oral squamous cell carcinoma, reactive oxygen species, AKT highlight that the Nox1/AKT signaling pathway plays an important role in cell survival in OSCC cells.

\section{Introduction}

Oral squamous cell carcinoma (OSCC) is the most common head and neck neoplasm affecting $~ 274,000$ individuals worldwide (1). The 5-year survival rate of patients with OSCC is only $53 \%$ (1-3). The development of OSCC has been shown to be associated with oral habits including betel quid chewing, as well as tobacco and/or alcohol consumption, which lead to continuous generation of reactive oxygen species (ROS) (4-6). Excessive ROS generation due to imbalances in the redox status mediates DNA damage and/or lipid peroxidation, which are thought to subsequently promote the development of OSCC (7). A recent study showed that oxidative stress markers, 8-hydroxy-2'-deoxyguanosin and malondialdehyde, were higher in the saliva of patients with OSCC than levels in the saliva of healthy normal subjects, while the antioxidant vitamins $\mathrm{C}$ and $\mathrm{E}$ were lower (8). Thus, accumulating evidence has implicated a role for ROS generation in the pathogenesis of OSCC.

Recently, the NADPH oxidase (Nox/Duox) family, a family of enzymes that generate ROS, has been shown to play an important role in cancer development and progression $(9,10)$. To date, the roles of Nox1, Nox 2, Nox4 and Nox 5 in cancer have been implicated, while those of Duox1, Duox2 and Nox3 in carcinogenesis are not well-reported (9). Upregulated Noxl expression and subsequent ROS generation was found to promote cancer cell growth, as well as escape from cancer cell death through the redox-dependent activation of p38MAPK and AKT signaling pathways (11). Given the experimental evidence that the Nox family plays a pivotal role in cancer cell development, it would be interesting to examine the involvement of Nox/Duox family members in the pathogenesis of OSCC.

In the present study, we found that Noxl and Nox4 mRNAs were highly expressed in a significant subset of OSCC cell lines. Knockdown of Nox 1 significantly induced apoptosis, and enhanced the cisplatin-induced cytotoxic effect in OSCC cells. Additionally, we report the underlying molecular mechanism responsible for this signaling. 
Table I. Primer sets for RT-PCR analyses.

\begin{tabular}{|c|c|c|c|}
\hline Gene & & Sequence information & Size (bp) \\
\hline Noxl & $\begin{array}{l}\text { Sense } \\
\text { Antisense } \\
\text { TaqMan ID }\end{array}$ & $\begin{array}{l}\text { 5'-GGAGCAGGAATTGGGGTCAC } \\
\text { 5'-TTGCTGTCCCATCCGGTGAG } \\
\text { Hs00246598_m1 }\end{array}$ & 236 \\
\hline Nox 2 & $\begin{array}{l}\text { Sense } \\
\text { Antisense }\end{array}$ & $\begin{array}{l}\text { 5'-GGAGTTTCAAGATGCGTGGAAACTA } \\
\text { 5'-GCCAGACTCAGAGTTGGAGATGCT }\end{array}$ & 550 \\
\hline Nox3 & $\begin{array}{l}\text { Sense } \\
\text { Antisense }\end{array}$ & $\begin{array}{l}\text { 5'-GGATCGGAGTCACTCCCTTCGCTG } \\
\text { 5'-ATGAACACCTCTGGGGTCAGCTGA }\end{array}$ & 458 \\
\hline Nox4 & $\begin{array}{l}\text { Sense } \\
\text { Antisense } \\
\text { TaqMan ID }\end{array}$ & $\begin{array}{l}\text { 5'-CTCAGCGGAATCAATCAGCTGTG } \\
\text { 5'-AGAGGAACACGACAATCAGCCTTAG } \\
\text { Hs00418356_m1 }\end{array}$ & $\begin{array}{l}286 \\
109\end{array}$ \\
\hline Nox 5 & $\begin{array}{l}\text { Sense } \\
\text { Antisense }\end{array}$ & $\begin{array}{l}\text { 5'-ATCAAGCGGCCCCCTTTTTTTCAC } \\
\text { 5'-CTCATTGTCACACTCCTCGACAGC }\end{array}$ & 239 \\
\hline Duoxl & $\begin{array}{l}\text { Sense } \\
\text { Antisense }\end{array}$ & $\begin{array}{l}\text { 5'-TTCACGCAGCTCTGTGTCAA } \\
\text { 5'-AGGGACAGATCATATCCTGGCT }\end{array}$ & 97 \\
\hline Duox2 & $\begin{array}{l}\text { Sense } \\
\text { Antisense }\end{array}$ & $\begin{array}{l}\text { 5'-ACGCAGCTCTGTGTCAAAGGT } \\
\text { 5'-TGATGAACGAGACTCGACAGC }\end{array}$ & 91 \\
\hline$G A P D H$ & $\begin{array}{l}\text { Sense } \\
\text { Antisense } \\
\text { TaqMan ID }\end{array}$ & $\begin{array}{l}\text { 5'-GAGTCAACGGATTTGGTCGT } \\
\text { 5'-GACAAGCTTCCCGTTCTCAG } \\
\text { Hs99999905_m1 }\end{array}$ & $\begin{array}{l}185 \\
122\end{array}$ \\
\hline
\end{tabular}

\section{Materials and methods}

Reagents. Dulbecco's modified Eagle's medium (DMEM) and penicillin-streptomycin were purchased from Wako Pure Chemical Industries, Ltd. (Osaka, Japan). Fetal bovine serum (FBS) was obtained from Nichirei Biosciences, Inc. (Tokyo, Japan). Diphenyleneiodonium (DPI), 2',7'-dichlorofluorescein diacetate (DCFH-DA), $N$-acetylcysteine (NAC), MTT and ammonium pyrrolidine dithiocarbamate (PDTC) were obtained from Sigma-Aldrich (St. Louis, MO, USA). AKT inhibitor, perifosine, was obtained from Cayman Chemical Co. (Ann Arbor, MI, USA). Propidium iodide (PI) was obtained from Merck Millipore (Billerica, MA, USA). Annexin V-FITC was obtained from MBL (Nagoya, Japan). Rabbit anti-NOX1 and anti-NOX4 antibodies were obtained from Santa Cruz Biotechnology, Inc. (Dallas, TX, USA). Anti-AKT, anti-phosphorylated-AKT (Ser473), anti- $\beta$-actin and HRP-conjugated anti-rabbit IgG were purchased from Cell Signaling Technologies Inc. (Beverly, MA, USA).

Cell culture. Five OSCC cell lines (HSC-2, HSC-3, HSC-4, SAS and OSC-19) were obtained from the Japanese Collection of Research Bioresources Cell Bank. HSC-2, HSC-3 and HSC-4 cell lines were established from individual patients with OSCC (12). The cell lines were maintained in DMEM supplemented with $10 \%$ heat-inactivated FBS and penicillin-streptomycin at $37^{\circ} \mathrm{C}$ in a $5 \% \mathrm{CO}_{2}$ humidified atmosphere. The cells were detached from $90-\mathrm{mm}$ dishes using trypsin and seeded in either 96- or 6-well plates for experimental purposes.
Cell viability MTT assay. The OSCC cells were seeded in 96-well plates $\left(5 \times 10^{3}\right.$ cells/well) and incubated for $24 \mathrm{~h}$ at $37^{\circ} \mathrm{C}$. Then, the cells were incubated with medium containing the indicated concentrations of DPI, PDTC and NAC. After $72 \mathrm{~h}$ of incubation, MTT solution was added into each well. Following $4 \mathrm{~h}$ of incubation, lysis buffer (10\% SDS in $0.01 \mathrm{M}$ of hydrogen chloride) was added and incubated overnight. Finally, the absorbance at $550 \mathrm{~nm}$ was measured using a SpectraMax M5 spectrophotometer (Molecular Devices, Sunnyvale, CA, USA).

Annexin $V$ assay. Apoptosis was evaluated using Annexin V $(\mathrm{AxV})$-FITC/PI double staining-based FACS analysis as previously described (13). Briefly, OSCC cells were seeded in 6-well plates $\left(1 \times 10^{5}\right.$ cells/well) and incubated for $24 \mathrm{~h}$ at $37^{\circ} \mathrm{C}$. Then, the cells were incubated with the indicated concentrations of DPI followed by incubation in AxV-FITC and PI $(10 \mu \mathrm{g} / \mathrm{ml})$ at room temperature for $15 \mathrm{~min}$. Finally, fluorescence intensities were determined by FACS using a FACSCanto II (BD, Franklin Lakes, NJ, USA).

ROS assay. ROS generation was detected using DCFH-DA as previously described (14). Briefly, HSC-2 and HSC-3 cells were incubated with DPI (5 or $10 \mu \mathrm{mol} / \mathrm{l}$ ). The cells were further incubated with the DCFH-DA fluorescent probe in the presence of DPI for $0.5 \mathrm{~h}$. After $48 \mathrm{~h}$ incubation, the cells were examined using FACSCanto II, which analyzed 10,000 events (determined by forward and side scatter). Data are presented as mean fluorescence intensity of triplicate determinations $\pm \mathrm{SE}$. 
RT-PCR analysis. The OSCC cells $\left(1 \times 10^{5}\right.$ cells/well) were seeded in 6-well plates. Following incubation for $48 \mathrm{~h}$, total RNA was extracted from the cells using NucleoSpin ${ }^{\circledR}$ RNA (Takara Bio,Inc., Shiga, Japan), and $2 \mu \mathrm{g}$ total RNA was reversetranscribed with High-Capacity cDNA Reverse Transcription kit (Life Technologies, Inc., Tokyo, Japan). mRNA expression levels of seven Nox/Duox family members (Noxl, Nox2, Nox3, Nox4, Nox5, Duoxl and Duox2) were examined using Veriti ${ }^{\circledR}$ Thermal Cycler (Applied Biosystems, Carlsbad, CA, USA) with specific primer sets as listed in Table I. mRNA expression of $G A P D H$ was used as an internal control.

Quantitative RT-PCR (qRT-PCR) analysis. HSC-2 and HSC-3 cells $\left(1 \times 10^{5}\right.$ cells/well $)$ were seeded in 6 -well plates and incubated for $24 \mathrm{~h}$. The following day, real-time qRT-PCR analysis was performed using the StepOnePlus ${ }^{\mathrm{TM}}$ Real-Time PCR System (Applied Biosystems). qRT-PCR analysis using TaqMan probes was performed according to the manufacturer's instructions. Gene specific TaqMan probes used in this study are listed in Table 1.

Western blot analysis. HSC- 2 and HSC- 3 cells $\left(2 \times 10^{5}\right.$ cells/well) were incubated with DPI as described above. The cells were washed with ice-cold PBS and lysed in loading buffer [125 mmol/1 Tris (pH 6.8), 4\% SDS, 10\% $\beta$-mercaptoethanol, $20 \%$ glycerol and $0.02 \%$ bromophenol blue]. Western blot analysis was performed as previously described (15). The relative protein levels were calculated after normalization to an internal control $\beta$-actin.

RNA interference. HSC- 2 and HSC- 3 cells $\left(1 \times 10^{5}\right.$ cells/ well) were plated in 6-well plates. On the following day, the cells were transfected using Lipofectamine RNAi/MAX (Life Technologies Inc.) to deliver the indicated concentrations of Noxl or Nox4 siRNA (Santa Cruz Biotechnology, Inc.) according to the manufacturer's protocol. siGENOME RISCFree siRNA (Dharmacon-Thermo Fisher Scientific, Tokyo, Japan) was used as a negative control.

Statistical analysis. At least three independent experiments and three replications per experiment were performed. The results are expressed as the mean \pm SE. Statistical significance between groups was determined using Student's t-tests. Statistical analyses were performed using SPSS 23.0 (SPSS, Inc., Chicago, IL, USA). Statistical significance was defined as $\mathrm{P}<0.05$.

\section{Results}

ROS scavengers inhibit cellular growth in a panel of OSCC cell lines. To investigate the involvement of ROS in OSCC cell growth, we first examined whether a Nox inhibitor, DPI, as well as ROS scavengers, including PDTC and NAC, affect the cell survival in five OSCC cell lines, HSC-2, HSC-3, HSC-4, SAS and OSC-19. The MTT assay revealed that the cell viability was dose-dependently suppressed by treatment with DPI (Fig. 1A), PDTC (Fig. 1B) or NAC (Fig. 1C). The $\mathrm{IC}_{50}$ values ranged from $0.07 \mu \mathrm{M}$ (SAS cells) to $1.59 \mu \mathrm{M}$ (OSC-19 cells) for DPI, $40 \mu \mathrm{M}$ (HSC-4 cells) to $>100 \mu \mathrm{M}$ (SAS cells) for PDTC and $2.53 \mathrm{mM}$ (HSC-2 cells) to $14.0 \mathrm{mM}$ (HSC-4 cells) for NAC among the OSCC cell lines tested (Table II).
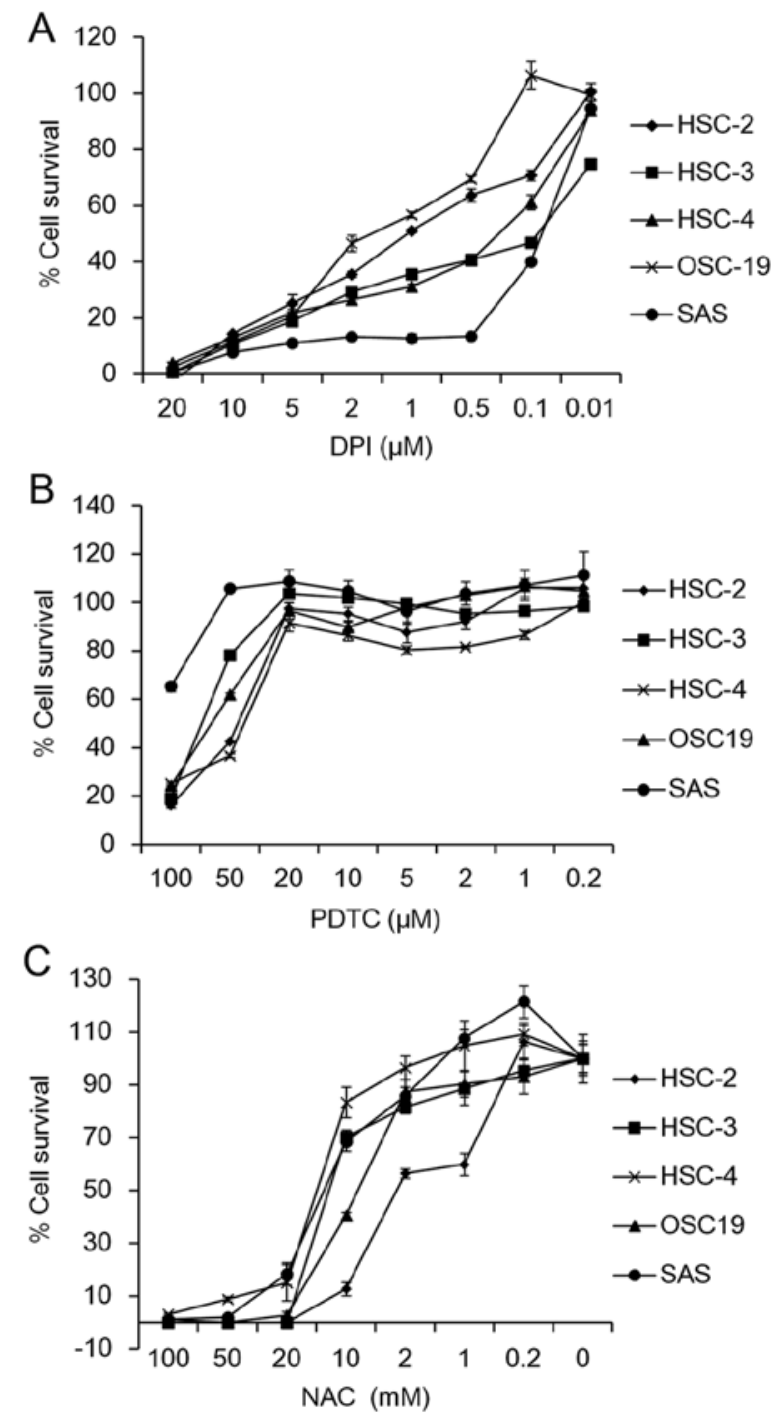

Figure 1. Effect of DPI, PDTC and NAC on cell survival of OSCC cells. Five OSCC cell lines (HSC-2, HSC-3, HSC-4, OSC19 and SAS) were seeded into 96 -well plates $\left(2.5 \times 10^{3}\right.$ cells/well). On the following day, the cells were treated with the indicated concentrations of (A) DPI $(20,10,5$, 2, 1, 0.5, 0.1 and $0.01 \mu \mathrm{M})$, (B) PDTC $(100,50,20,10,5,2,1$ and $0.2 \mu \mathrm{M})$ and (C) NAC $(100,50,20,10,2,1$ and $0.2 \mu \mathrm{M})$ for $72 \mathrm{~h}$. The percentage of cell survival of the five OSCC cell lines was measured by MTT assay. Data are expressed relative to the mean optical density $(550 \mathrm{~nm})$ in the untreated cells, which was arbitrarily defined as $100 \%$. Data are represented as the mean $\pm \operatorname{SE}(n=3)$.

Table II. IC $_{50}$ values of the OSCC cell lines treated with DPI, PDTC or NAC.

\begin{tabular}{lccr}
\hline Cell lines & $\begin{array}{c}\text { DPI } \\
\mathrm{IC}_{50}(\mu \mathrm{M})\end{array}$ & $\begin{array}{c}\text { PDTC } \\
\mathrm{IC}_{50}(\mu \mathrm{M})\end{array}$ & \multicolumn{1}{c}{$\mathrm{NAC}$} \\
$\mathrm{IC}_{50}(\mathrm{mM})$ \\
\hline HSC2 & 1.05 & 44.1 & 2.53 \\
HSC3 & 0.08 & 69.5 & 12.20 \\
HSC4 & 0.24 & 40.0 & 14.00 \\
OSC19 & 1.59 & 62.1 & 7.24 \\
SAS & 0.07 & $>100.0$ & 12.90 \\
\hline
\end{tabular}

OSCC, oral squamous cell carcinoma; DPI, diphenyleneiodonium; PDTC, pyrrolidine dithiocarbamate; NAC, $N$-acetylcysteine. 


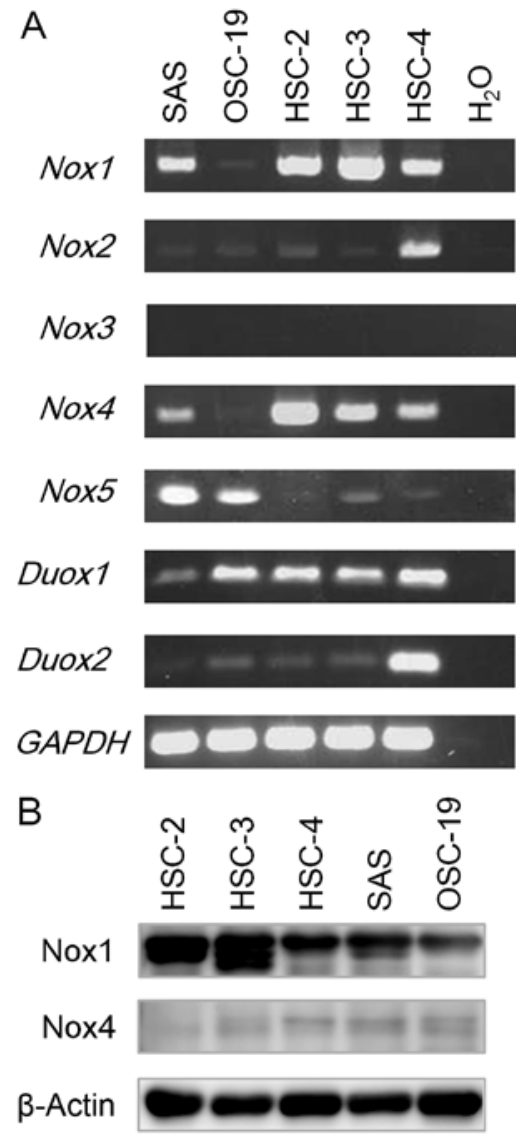

Figure 2. mRNA expression of Nox/Duox family members and protein expression of Nox 1 and Nox 4 in OSCC cell lines. Five OSCC cell lines (HSC-2, HSC-3, HSC-4, OSC-19 and SAS) were seeded in 6-well plates ( $1 \times 10^{5}$ cells/well) and incubated for $48 \mathrm{~h}$. (A) mRNA expression of Nox/Duox family members (Nox1, Nox2, Nox3, Nox4, Nox5, Duox1 and Duox2) were analyzed using RT-PCR. mRNA expression of $G A P D H$ was used as an internal control. Representative result of gel electrophoresis is shown. The results of RT-PCR analyses are summarized in Table III. (B) Protein expression of Nox1 and Nox4 was analyzed by western blotting. A total of $2 \mu \mathrm{g}$ of cell lysate was subjected to western blot analysis to detect NOX1 or NOX4, while $1 \mu \mathrm{g}$ was subjected to detect $\beta$-actin protein.

These results suggest that scavenging of ROS may suppress cell growth in OSCC cells.

Expression levels of the Nox/Duox family in OSCC cell lines. Since DPI reduced the cell viability in OSCC cells, we assumed that the Nox/Duox family plays an important role in cell survival. To clarify this issue, we first examined Nox/Duox
mRNAs in five OSCC cell lines using RT-PCR analysis. As shown in Fig. 2A, while Noxl and Nox4 mRNA expression was readily detected in four cell lines, except for OSC-19, Nox 2 and Nox3 mRNA expression was primarily detected only in HSC-4 cells. Nox 5 mRNA expression was detected in both SAS and OSC-19 cells (Fig. 2A). Additionally, DuoxI mRNA expression was detectable in all of the cell lines examined, while that of Duox2 was readily detected in the HSC- 4 cells but diminished in the OSC-19, HSC-2 and HSC-3 cells (Fig. 2A). These results are summarized in Table III. We also examined protein expression of Nox1 and Nox4; Nox1 protein expression was elevated in the HSC-2 and HSC-3 cells, while Nox4 was slightly expressed in the five OSCC cell lines examined (Fig. 2B).

Nox inhibitor DPI suppresses ROS generation and induces apoptosis. To investigate the involvement of the Nox/Duox family in ROS generation, we further examined the effect of DPI on ROS generation in HSC-2 and HSC-3 cells. As expected, RO generation was significantly suppressed by DPI treatment (Fig. 3A and B). This result prompted us to further examine the effect of DPI on the induction of apoptosis in HSC-2 and HSC-3 cells. As shown in Fig. 3C, the percentages of $\mathrm{AxV}^{+} / \mathrm{PI}^{+}$cells was significantly increased $48 \mathrm{~h}$ after DPI treatment in both the HSC-2 and HSC-3 cell lines, suggesting that the Nox family may play a role in the anti-apoptotic effect as well as ROS generation.

Knockdown of Noxl, but not Nox4, suppresses cell survival. Since Noxl and Nox4 mRNA expression was readily detectable in the HSC-2 and HSC-3 cells, we next examined the effect of Noxl or Nox4 knockdown on cell viability using MTT assay. We verified that transfection of Noxl or Nox4 siRNAs significantly reduced their endogenous mRNA levels $(65-70 \%$ in Noxl or 50-55\% in Nox4), respectively, in the cells compared to those transfected with control siRNA (Fig. 4A and B). Knockdown of Noxl, but not Nox4, significantly suppressed the cell viability in both the HSC-2 and HSC-3 cell lines (Fig. 4C). In addition, the percentages of $\mathrm{AxV}^{+} / \mathrm{PI}^{+}$cells were significantly increased after the transfection of Noxl siRNAs (Fig. 4D), strongly suggesting that Noxl contributes to anti-apoptosis in OSCC cells. Unexpectedly, under Noxl knockdown, no significant reduction in intracellular ROS was detected (Fig. 4E), suggesting that Nox1 may contribute to cell survival through a mechanism other than ROS generation.

Table III. RT-PCR analysis of mRNA expression of the Nox/Duox family.

\begin{tabular}{lccccccc}
\hline & \multicolumn{3}{c}{ Nox family } & & \multicolumn{2}{c}{ Duox family } \\
\cline { 2 - 6 } Cell lines & Noxl & Nox2 & Nox3 & Nox4 & Nox5 & Duoxl & Duox2 \\
\hline SAS & + & - & - & + & ++ & - & + \\
OSC-19 & - & - & - & - & + & + \\
HSC-2 & + & - & - & + & - & + & + \\
HSC-3 & ++ & + & + & - & + & + & + \\
HSC-4 & + & & & + & + \\
\hline
\end{tabular}



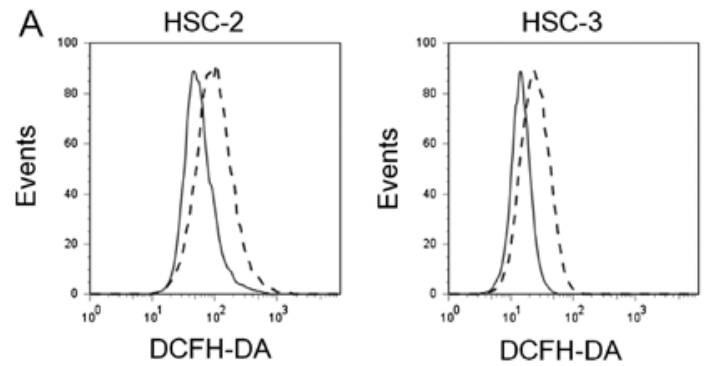

B
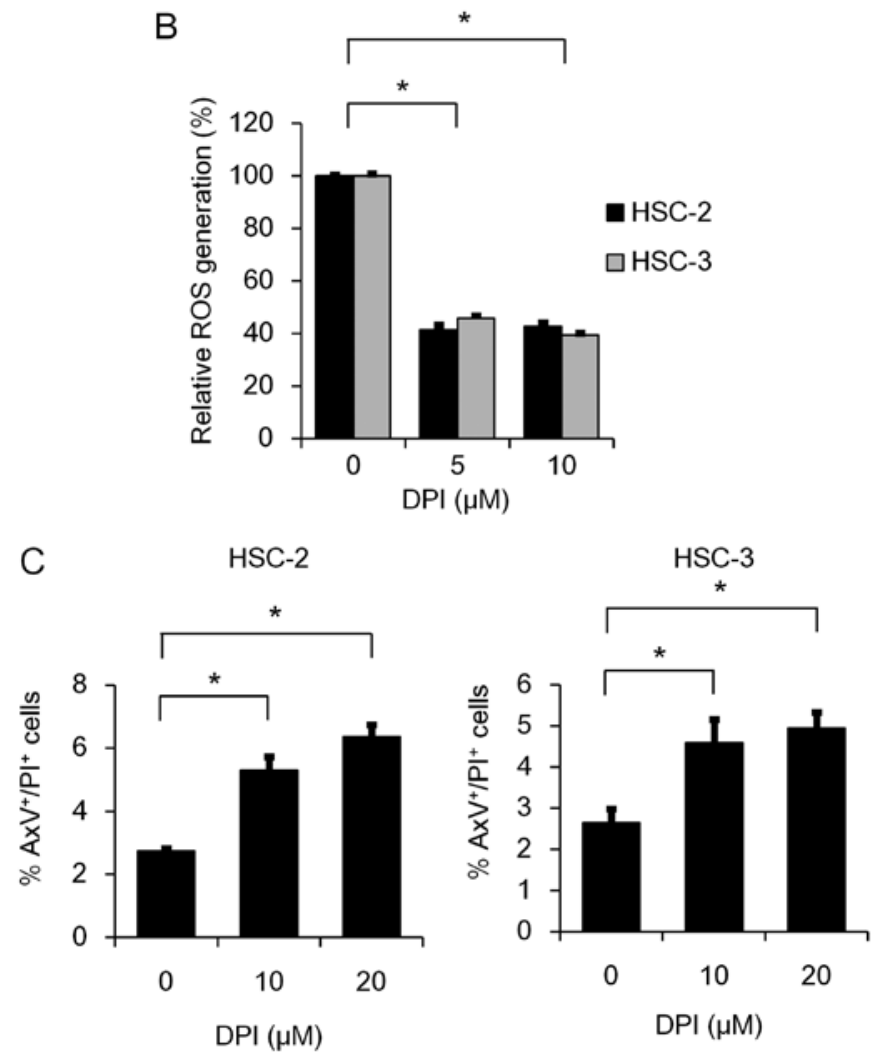

Figure 3. Inhibitory effects of DPI on ROS generation and apoptosis. (A and B) The effect of DPI on intracellular ROS generation. (A) Representative results of flow cytometic analyses using DCFH-DA probe in HSC-2 (left panel) and HSC-3 (right panel) cells. HSC-2 and HSC-3 cells $\left(2 \times 10^{5}\right.$ cells/well) were incubated with DPI $(5$ or $10 \mu \mathrm{M})$ for $48 \mathrm{~h}$, followed by labeling with DCFH-DA $(5 \mu \mathrm{M})$, and alterations in the intracellular ROS generation were measured by FACS analysis. Vertical line, no treatment; solid line, DPI treatment $(10 \mu \mathrm{M})$. (B) Data are expressed relative to the mean fluorescence intensity (\% ROS generation) of the untreated cells, which was arbitrarily defined as $100 \%(\mathrm{n}=3)$. (C) Effect of DPI on apoptosis. HSC-2 and HSC- 3 cells were treated with either 10 or $20 \mu \mathrm{M}$ of DPI for $48 \mathrm{~h}$, respectively. After the incubation for $48 \mathrm{~h}$, the cells were stained with AxV-FITC and PI. The percentages of $\mathrm{AxV}^{+} / \mathrm{PI}^{+}$cells are indicated. Bar graphs showing the percentage of apoptosis $\left(\mathrm{AxV}^{+} / \mathrm{PI}^{+}\right.$cells) are presented. Data are expressed as the mean $\pm \mathrm{SE}(\mathrm{n}=3)$. ${ }^{*} \mathrm{P}<0.05$, significant difference.

Noxl knockdown, as well as perifosine treatment, prevents phosphorylation of AKT. AKT (protein kinase B) is a regulator of cell survival in response to growth factors. AKT is activated through its phosphorylation, and this kinase inhibits apoptosis-inducing proteins, thereby promoting cell survival. Thus, we investigated phosphorylated AKT levels in OSCC cell lines using western blot analysis. As shown in Fig. 5A, phosphorylated forms of AKT were readily detected in the HSC-2, HSC-3 and HSC-4 cells (Fig. 5A). We therefore examined the effect of a specific AKT inhibitor perifosine on
A

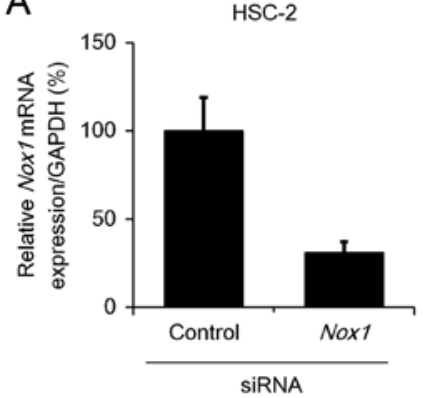

B
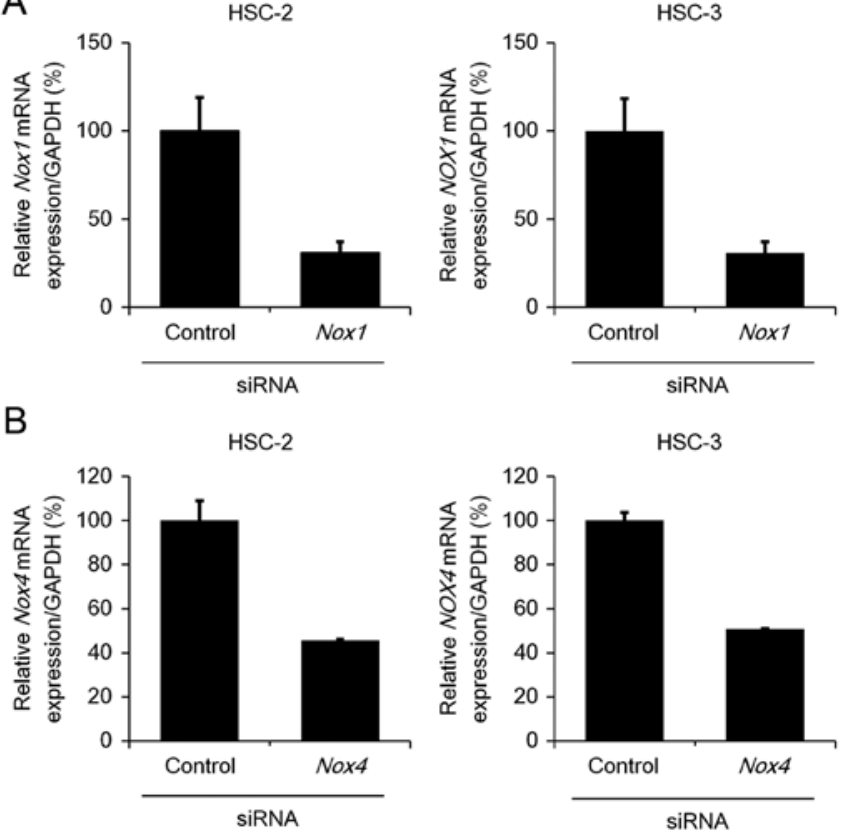

C
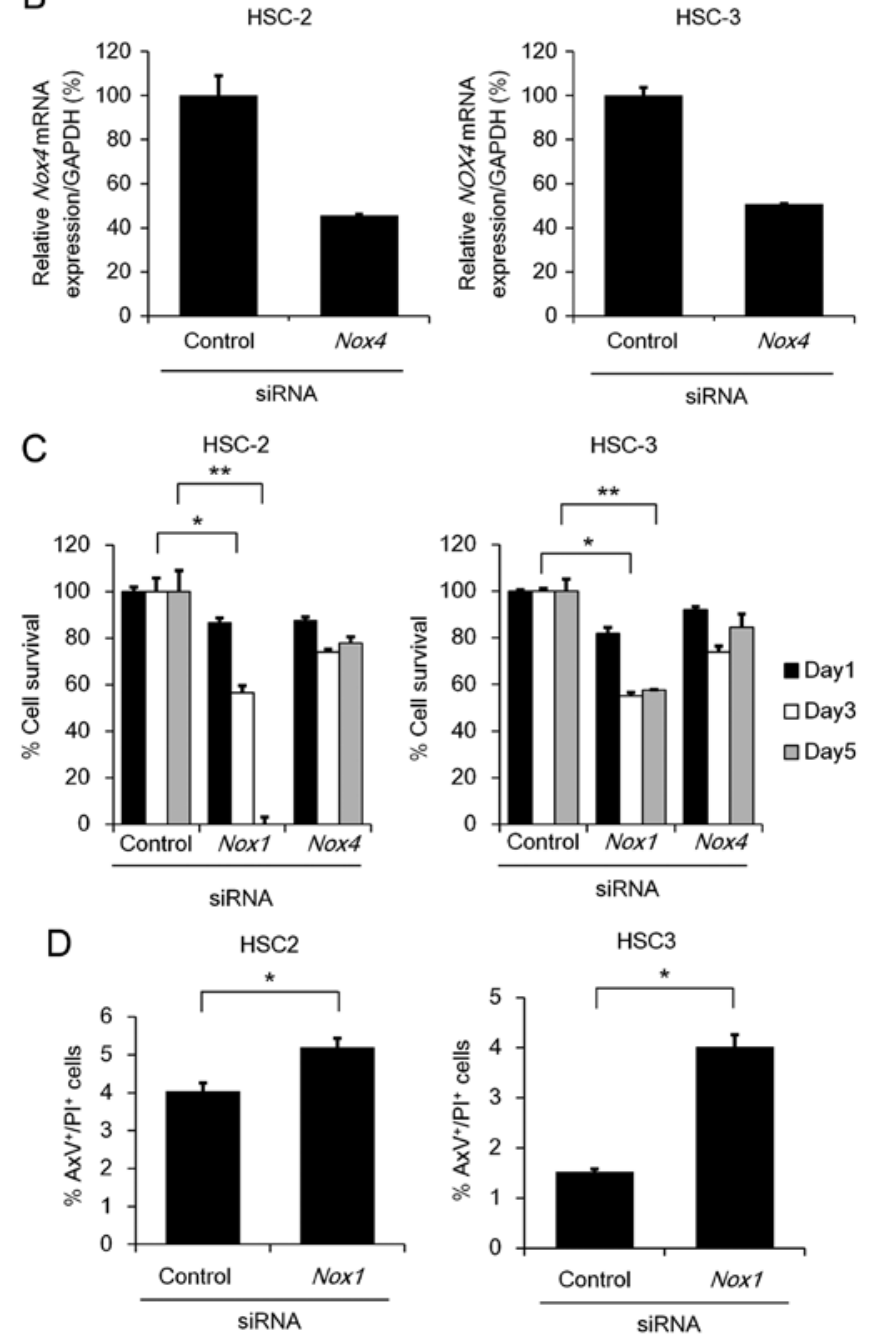

Figure 4. Cell survival and apoptosis under Nox1 or Nox4 knockdown. (A and B) HSC-2 and HSC-3 cells ( $1 \times 10^{5}$ cell/well) were transfected with $50 \mathrm{nM}$ of siRNA specific to Noxl, Nox4 or a non-specific control siRNA. After $48 \mathrm{~h}$, total RNA was extracted from the cells and mRNA expression levels of Noxl (A) or Nox4 (B) were analyzed using qRT-PCR with specific TaqMan probes. The relative gene expression levels are shown after normalization to GAPDH mRNA expression. Data are expressed relative to the mRNA levels found in the cells transfected with control siRNA, which was arbitrarily defined as $100 \%(\mathrm{n}=3)$. (C) HSC-2 and HSC-3 cells $\left(2.5 \times 10^{3}\right.$ cells/well) were transfected with $50 \mathrm{nM}$ of siRNA specific to Noxl, Nox4 or a non-specific control siRNA. After $72 \mathrm{~h}$, MTT assay was performed as described in Fig. 1A. Data are expressed as the mean $\pm \mathrm{SE}(\mathrm{n}=3$ ). (D) Apoptosis under Nox1 or Nox4 knockdown. HSC-2 and HSC-3 cells were seeded and transfected as described in (A). After $48 \mathrm{~h}$, the cells were stained with AxV-FITC and PI. Data are expressed as the mean $\pm \mathrm{SE}(\mathrm{n}=3)$. ${ }^{*} \mathrm{P}<0.05 ;{ }^{* *} \mathrm{P}<0.005$, significant difference.

cell survival using MTT assay. As shown in Fig. 5B, perifosine treatment dose-dependently reduced cell viability in the OSCC 

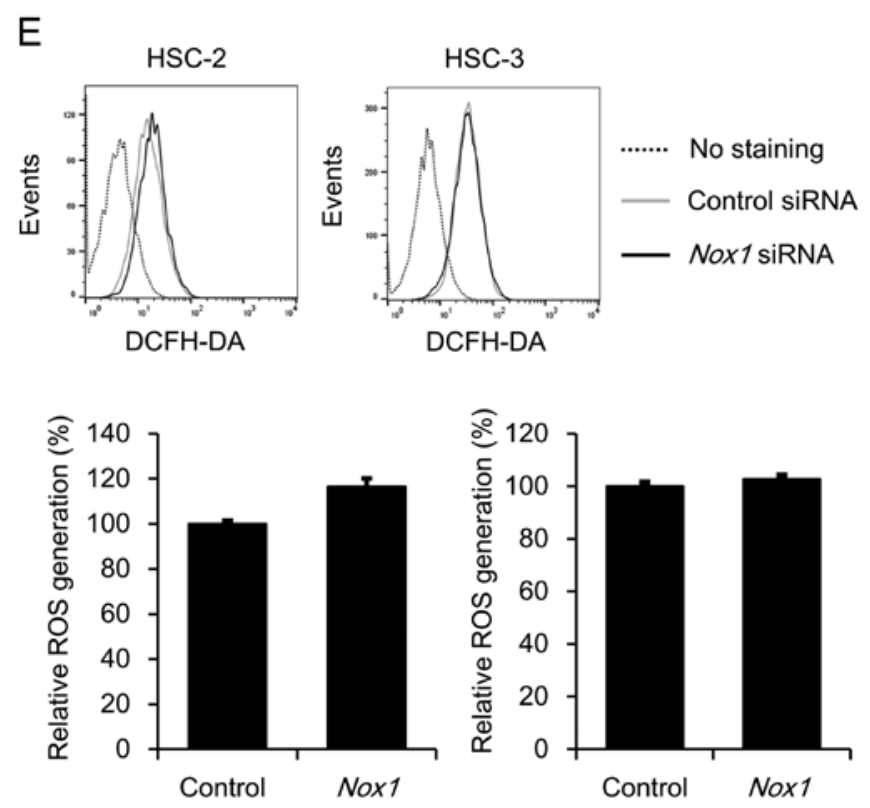

Figure 4. Continued. (E) The effect of Nox1 or Nox4 knockdown on intracellular ROS generation. HSC-2 and HSC-3 cells were seeded and transfected as described in (A). After $48 \mathrm{~h}$, the cells were labeled with DCFH-DA $(5 \mu \mathrm{M})$ and alterations in the intracellular ROS generation were measured by FACS analysis. Representative results of flow cytometic analyses in HSC-2 (left panel) and HSC-3 (right panel) cells are shown. Bar graphs show the percentage of ROS generation relative to the mean fluorescence intensity of the untreated cells, which was arbitrarily defined as $100 \%$ $(\mathrm{n}=3)$. Vertical line, no staining; gray or black line, control or Noxl siRNA $(50 \mathrm{nM})$, respectively.

cell lines (Fig. 5B), suggesting that AKT plays a pivotal role in OSCC cell survival. Since the Nox family has been shown to enhance phosphorylation of AKT (9), we then examined the effect of Noxl knockdown on AKT phosphorylation using western blot analysis. As shown in Fig. 5C, Noxl knockdown significantly reduced the phosphorylation level of AKT. These results suggest that Nox1 contributes to cell survival through activation of the AKT signaling pathway.

Noxl knockdown and cisplatin treatment act cooperatively to suppress cell survival and induce apoptosis. Cisplatin is one of the most frequently used anticancer drugs for OSCC treatment. Therefore, we sought to examine whether inhibition of AKT activity or Noxl knockdown influences the cytotoxic effect of cisplatin. As shown in Fig. 6A, the perifosine and cisplatin combination treatment significantly suppressed cell viability in both te HSC-2 and HSC-3 cell lines, compared to the cisplatin monotherapy. Similarly, combined perifosine-cisplatin treatment decreased cell viability in the SAS and OSC-19 cells (data not shown). Notably, the Nox1 knockdown and cisplatin combination treatment significantly suppressed cell viability, compared to the cisplatin monotherapy (Fig. 6B). This novel finding prompted us to examine the effect of Noxl knockdown and cisplatin combination treatment on induction of apoptosis. As expected, the treatment significantly induced apoptosis (Fig. 6C), indicating that Nox1 knockdown enhances the cytotoxic effect of cisplatin in OSCC cells.

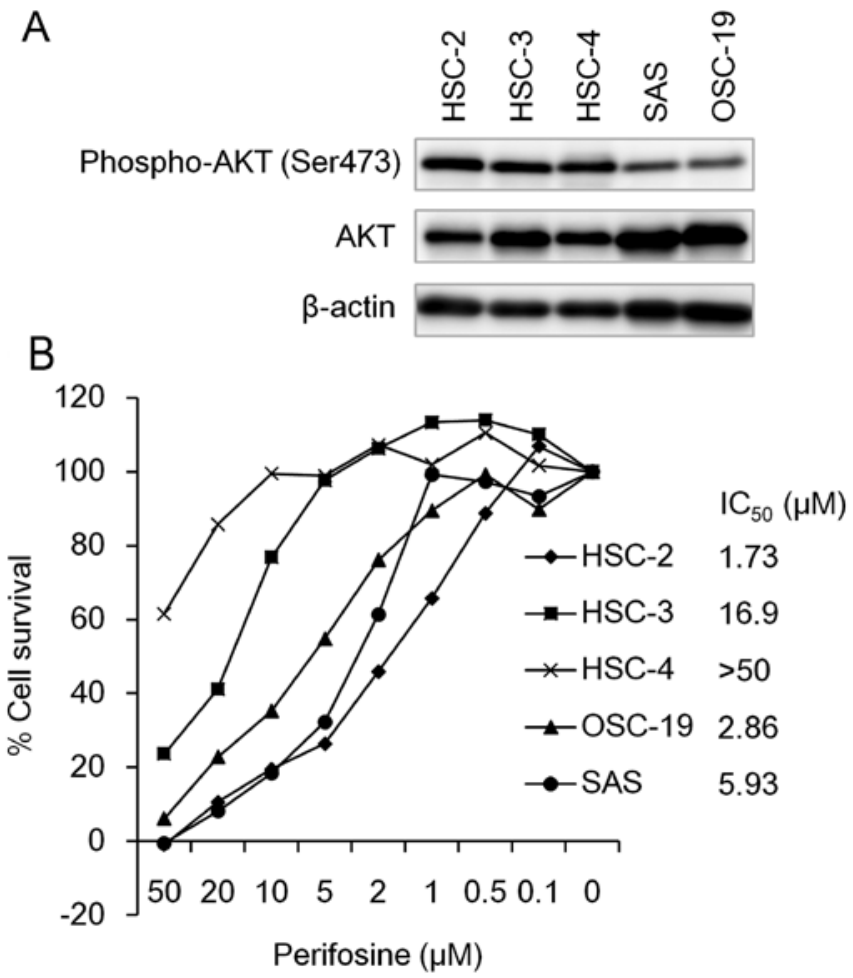

C
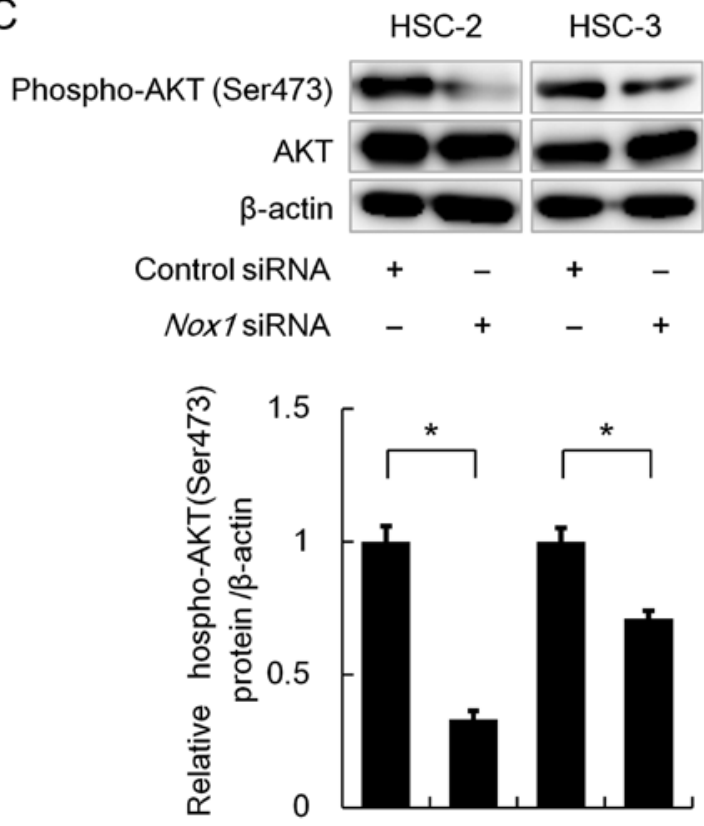

Figure 5. Effect of Nox1 knockdown on the phosphorylation level of AKT. (A) Phosphorylation levels of AKT in OSCC cell lines. OSCC cell lines were seeded in a 6 -well plate $\left(1 \times 10^{5}\right.$ cells/well) and incubated for $48 \mathrm{~h}$. A total of $2.5 \mu \mathrm{g}$ of cell lysate was subjected to western blot analysis to detect AKT or phosphorylated AKT, while $1 \mu \mathrm{g}$ was subjected to detect $\beta$-actin protein. (B) The effect of AKT inhibitor, perifosine, on cell viability in OSCC cell lines. OSCC cell lines were seeded in a 96-well plate $\left(2.5 \times 10^{3}\right.$ cells/well). On the following day, the cells were treated with the indicated concentrations $(50,20,10,5,2,1,0.5$ and $0.1 \mu \mathrm{M})$ of perifosine for $72 \mathrm{~h}$. The percentage of cell survival of five OSCC cell lines was measured by MTT assay. Data are expressed relative to the mean optic density $(550 \mathrm{~nm})$ found in the untreated cells, which was arbitrarily defined as $100 \%$. Data are expressed as the mean $\pm \mathrm{SE}(\mathrm{n}=3)$. The $\mathrm{IC}_{50}$ values of perifosine were determined for each cell line using MTT assay. (C) HSC-2 and HSC-3 cells $\left(1 \times 10^{5}\right.$ cells/well) were transfected with $50 \mathrm{nM}$ of siRNA specific to Nox 1 or control siRNA. After incubation for $48 \mathrm{~h}$, the cells were lysed and the cell lysates were subjected to western blot analysis, as described in (A). ${ }^{*} \mathrm{P}<0.05$, a significant difference $(\mathrm{n}=3)$. The data are represented as the mean $\pm \mathrm{SE}$ of three separate experiments. 
A
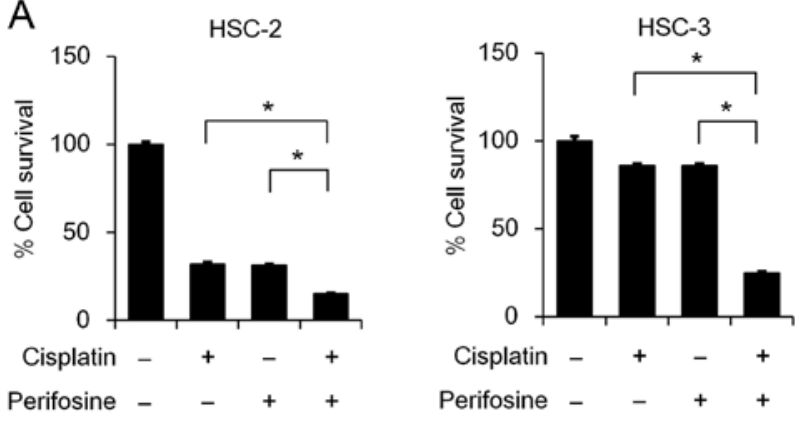

B
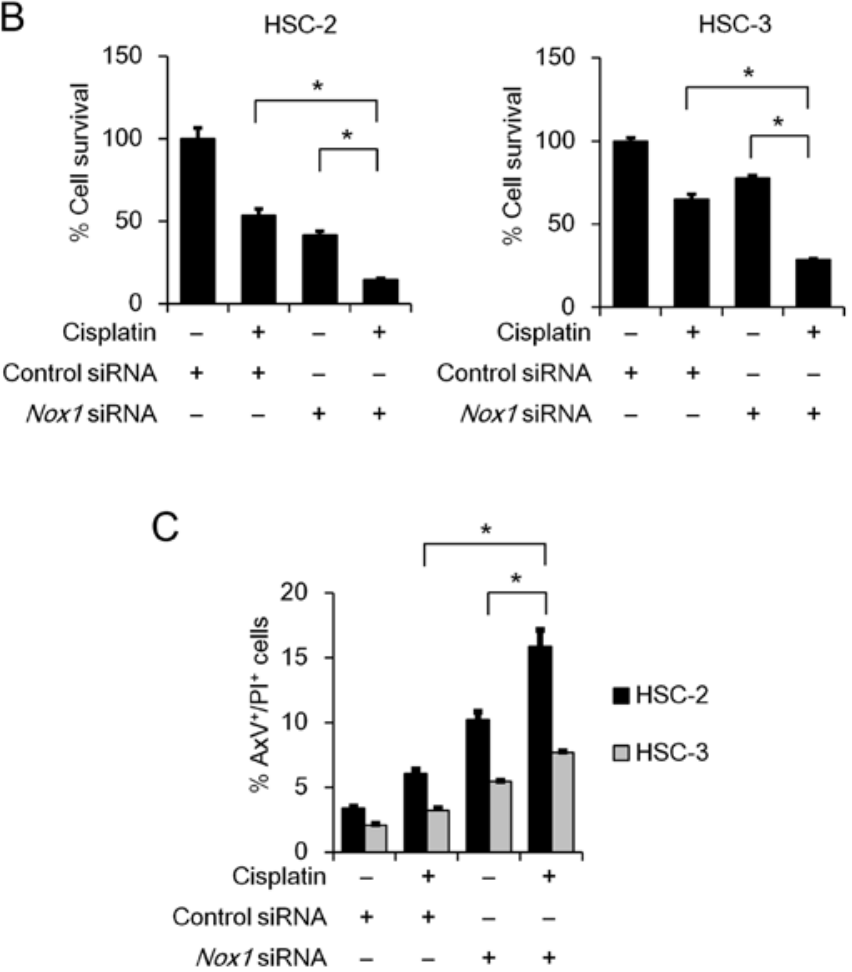

Figure 6. Combinatorial effect of cisplatin with either perifosine treatment or Nox1 knockdown on cell viability and apoptosis. (A) HSC-2 and HSC-3 cells were seeded in a 96 -well plate $\left(2.5 \times 10^{3}\right.$ cells/well $)$. On the following day, the cells were treated with cisplatin (HSC-2, $5 \mu \mathrm{M}$; HSC-3, $2.5 \mu \mathrm{M}$ ) and/or perifosine (HSC-2, $2 \mu \mathrm{M}$; HSC-3, $10 \mu \mathrm{M}$ ) for $72 \mathrm{~h}$. (B and C) HSC-2 and HSC-3 cells were transfected with $50 \mathrm{nM}$ of Noxl siRNA or control siRNA in the presence or absence of cisplatin (HSC-2, $5 \mu \mathrm{M}$; HSC-3, $2.5 \mu \mathrm{M}$ ). (B) After incubation for $72 \mathrm{~h}$, MTT analysis of the growth rate was performed as described in Fig 1A. Data are presented relative to the mean optical density $(550 \mathrm{~nm})$ in the untreated cells, which was arbitrarily defined as $100 \%$. Data are expressed as means \pm SE $(n=3)$. (C) After incubation for $48 \mathrm{~h}$, the cells were stained with AxV-FITC and PI. Bar graphs showing the percentage of apoptosis $\left(\mathrm{AxV}^{+} / \mathrm{PI}^{+}\right.$cells $)$are presented. Data are represented as the mean $\pm \operatorname{SE}(n=3)$. ${ }^{*} P<0.05$, significant difference.

\section{Discussion}

Nox/Duox family members are regarded as major sources of ROS generation, which plays an important role in cancer development $(9,16)$. It has been reported that inhibition of Nox activity induces apoptosis in a number of cancerous cells including pancreatic cancer, mesothelioma and sarcoma (17-19). In the present study, we demonstrated that knockdown of Noxl but not Nox4 significantly reduced the cell viability in a subset of OSCC cell lines. We also found that Noxl knockdown decreased phosphorylated AKT levels accompanied by induction of apoptosis. Our observation that the specific AKT inhibitor perifosine reduced the cell viability suggested that Nox1-mediated AKT phosphorylation contributes to cell survival in OSCC cells.

The Nox/Duox family consists of seven members. Our RT-PCR analysis revealed that Noxl and Nox4 mRNAs were highly expressed in a significant subset of OSCC cell lines. Knockdown of Nox1, but not Nox4, significantly suppressed the cell viability by $50 \%$ in OSCC cells. Additionally, Noxl knockdown significantly induced the apoptosis of OSCC cells. Notably, Noxl knockdown markedly enhanced cisplatin-induced apoptosis. This novel finding raises the possibility that Nox 1 is a potential therapeutic target for a significant subset of oral cancer cells. We unexpectedly observed that Noxl knockdown had almost no suppressive effect on ROS generation. It may be possible that Nox1 exerts anti-apoptotic effects through a mechanism other than ROS generation. Puca et al reported that Nox1 inhibits acetylation of p53 (K382), which is a target of SIRT1 deacetylase, and impaired p53 pro-apoptotic transcriptional activity (20). Thus, it may be interesting to investigate the role of p53 in Nox1mediated anti-apoptotic signaling in OSCC cells.

It was previously reported that Nox4-mediated induction of pro-inflammatory cytokines after epidermal growth factor receptor inhibition (21) and erlotinib-induced cytotoxicity is associated with hydrogen peroxide production thorough Nox4 signaling in head and neck squamous cell carcinoma (HNSCC) cells (22). We recently reported that Nox4 knockdown induced apoptosis in mesothelioma (19). However, in the present study, Nox4 knockdown did not induce apoptosis in OSCC cells. Thus, it would also be interesting to pursue the mechanism underlying the discrepancy in the effect of Nox4 knockdown between OSCC and mesothelioma cells.

AKT, a regulator of cell survival, is activated through its phosphorylation and inhibits apoptosis-inducing proteins, thereby preventing cell death and prolonging cell survival. Recent studies have also implicated the use of a selective inhibitor for phosphatidylinositol 3-kinases (PI3K)/AKT as treatment for patients with non-small cell lung cancer, hematologic malignancies and HNSCC (23-25). We observed that Noxl knockdown attenuated the phosphorylation level of AKT, raising the possibility that inhibition of Nox1 activity may suppress cell survival by inhibiting the AKT signaling pathway. Kozaki et al reported that a missense mutation of PIK3CA, which encodes the $110-\mathrm{kDa}$ catalytic subunit of PI3K, was detected in OSCC cell lines, including HSC-2 and HSC-3, as well as OSCC patients tumors (26). In the present study, Noxl knockdown significantly attenuated the phosphorylation of AKT and reduced cell viability in the OSCC cells. This suggested that inhibition of Nox1 potentially suppresses activation of AKT, thereby promoting apoptosis in OSCC cells harboring a mutation of the PIK3CA gene.

In conclusion, we demonstrated that Nox1 likely contributes to cell survival through its anti-apoptotic effects in a significant subset of OSCC cells. Based on our experimental data, we hypothesized that Nox1 contributes to cell survival through the AKT signaling pathway without initiating ROS generation. It would be of particular interest to investigate the molecular 
mechanism by which Nox1 mediates the AKT signaling pathway in OSCC cells. Although we only performed in vitro experiments using a subset of OSCC cell lines in the present study, our novel finding that Noxl knockdown enhanced cisplatin-induced cytotoxic effects provides an attractive option for the combined therapy of Noxl knockdown and cisplatin chemotherapy in OSCC treatment. Additional studies such as in vivo experiments and/or Nox 1 expression status in patients with OSCC are warranted to further understand the molecular mechanisms underlying the pathogenesis related to cell survival in OSCC and the associated clinical applications.

\section{Acknowledgements}

The present study was partly supported by a grant from the Strategic Research Foundation Grant-aided Project for Private Universities from the Ministry of Education, Culture, Sports, Science and Technology, Japan (MEXT) (S1101027 to S. K., H. K. and Y. H.).

\section{References}

1. Parkin DM, Bray F, Ferlay J and Pisani P: Global cancer statistics, 2002. CA Cancer J Clin 55: 74-108, 2005.

2. Sklenicka S, Gardiner S, Dierks EJ, Potter BE and Bell RB: Survival analysis and risk factors for recurrence in oral squamous cell carcinoma: Does surgical salvage affect outcome? J Oral Maxillofac Surg 68: 1270-1275, 2010.

3. Dissanayaka WL, Pitiyage G, Kumarasiri PV, Liyanage RL, Dias KD and Tilakaratne WM: Clinical and histopathologic parameters in survival of oral squamous cell carcinoma. Oral Surg Oral Med Oral Pathol Oral Radiol 113: 518-525, 2012.

4. Chen YK, Huang HC, Lin LM and Lin CC: Primary oral squamous cell carcinoma: An analysis of 703 cases in southern Taiwan. Oral Oncol 35: 173-179, 1999.

5. Fioretti F, Bosetti C, Tavani A, Franceschi S and La Vecchia C: Risk factors for oral and pharyngeal cancer in never smokers. Oral Oncol 35: 375-378, 1999.

6. Altieri A, Bosetti C, Gallus S, Franceschi S, Dal Maso L, Talamini R, Levi F, Negri E, Rodriguez T and La Vecchia C: Wine, beer and spirits and risk of oral and pharyngeal cancer: A case-control study from Italy and Switzerland. Oral Oncol 40 904-909, 2004.

7. Kolanjiappan K, Ramachandran CR and Manoharan S: Biochemical changes in tumor tissues of oral cancer patients. Clin Biochem 36: 61-65, 2003.

8. Kaur J, Politis C and Jacobs R: Salivary 8-hydroxy-2-deoxyguanosine, malondialdehyde, vitamin $\mathrm{C}$, and vitamin $\mathrm{E}$ in oral pre-cancer and cancer: diagnostic value and free radical mechanism of action. Clin Oral Investig 20: 315-319, 2016.

9. Block K and Gorin Y: Aiding and abetting roles of NOX oxidases in cellular transformation. Nat Rev Cancer 12: 627-637, 2012.

10. Weyemi U, Redon CE, Parekh PR, Dupuy C and Bonner WM: NADPH oxidases NOXs and DUOXs as putative targets for cancer therapy. Anticancer Agents Med Chem 13: 502-514, 2013.

11. Sancho P and Fabregat I: NADPH oxidase NOX1 controls autocrine growth of liver tumor cells through up-regulation of the epidermal growth factor receptor pathway. J Biol Chem 285: 24815-24824, 2010.
12. Momose F, Araida T, Negishi A, Ichijo H, Shioda S and Sasaki S: Variant sublines with different metastatic potentials selected in nude mice from human oral squamous cell carcinomas. J Oral Pathol Med 18: 391-395, 1989.

13. Nakaoka T, Ota A, Ono T, Karnan S, Konishi H, Furuhashi A, Ohmura Y, Yamada Y, Nakaoka T, Ota A, Ono T, Karnan S Konishi H, Furuhashi A, Ohmura Y, Yamada Y, Hosokawa Y and Kazaoka Y: Combined arsenic trioxide-cisplatin treatment enhances apoptosis in oral squamous cell carcinoma cells. Cell Oncol 37: 119-129, 2014.

14. Hossain E, Ota A, Karnan S, Damdindorj L, Takahashi M, Konishi Y, Konishi $\mathrm{H}$ and Hosokawa Y: Arsenic augments the uptake of oxidized LDL by upregulating the expression of lectinlike oxidized LDL receptor in mouse aortic endothelial cells. Toxicol Appl Pharmacol 273: 651-658, 2013.

15. Takahashi M, Ota A, Karnan S, Hossain E, Konishi Y, Damdindorj L, Konishi H, Yokochi T, Nitta M and Hosokawa Y: Arsenic trioxide prevents nitric oxide production in lipopolysaccharide -stimulated RAW 264.7 by inhibiting a TRIF-dependent pathway. Cancer Sci 104: 165-170, 2013.

16. Ralph SJ, Rodríguez-Enríquez S, Neuzil J, Saavedra E and Moreno-Sánchez R: The causes of cancer revisited: 'mitochondrial malignancy' and ROS-induced oncogenic transformation - why mitochondria are targets for cancer therapy. Mol Aspects Med 31: 145-170, 2010.

17. Mochizuki T, Furuta S, Mitsushita J, Shang WH, Ito M, Yokoo Y, Yamaura M, Ishizone S, Nakayama J, Konagai A, et al: Inhibition of NADPH oxidase 4 activates apoptosis via the AKT/apoptosis signal-regulating kinase 1 pathway in pancreatic cancer PANC-1 cells. Oncogene 25: 3699-3707, 2006.

18. Tanaka M, Miura Y, Numanami H, Karnan S, Ota A, Konishi H, Hosokawa Y and Hanyuda M: Inhibition of NADPH oxidase 4 induces apoptosis in malignant mesothelioma: Role of reactive oxygen species. Oncol Rep 34: 1726-1732, 2015.

19. Zhang $\mathrm{B}$, Liu $\mathrm{Z}$ and $\mathrm{Hu} \mathrm{X}$ : Inhibiting cancer metastasis via targeting NAPDH oxidase 4. Biochem Pharmacol 86: 253-266, 2013.

20. Puca R, Nardinocchi L, Starace G, Rechavi G, Sacchi A, Givol D and D'Orazi G: Nox1 is involved in p53 deacetylation and suppression of its transcriptional activity and apoptosis. Free Radic Biol Med 48: 1338-1346, 2010.

21. Fletcher EV, Love-Homan L, Sobhakumari A, Feddersen CR, Koch AT, Goel A and Simons AL: EGFR inhibition induces proinflammatory cytokines via NOX4 in HNSCC. Mol Cancer Res 11: 1574-1584, 2013.

22. Orcutt KP, Parsons AD, Sibenaller ZA, Scarbrough PM, Zhu Y, Sobhakumari A, Wilke WW, Kalen AL, Goswami P, Miller FJ Jr, et al: Erlotinib-mediated inhibition of EGFR signaling induces metabolic oxidative stress through NOX4. Cancer Res 71: 3932-3940, 2011.

23. Fumarola C, Bonelli MA, Petronini PG and Alfieri RR: Targeting PI3K/AKT/mTOR pathway in non small cell lung cancer. Biochem Pharmacol 90: 197-207, 2014.

24. Barrett D, Brown VI, Grupp SA and Teachey DT: Targeting the $\mathrm{PI} 3 \mathrm{~K} / \mathrm{AKT} / \mathrm{mTOR}$ signaling axis in children with hematologic malignancies. Paediatr Drugs 14: 299-316, 2012.

25. Simpson DR, Mell LK and Cohen EE: Targeting the PI3K/AKT/ mTOR pathway in squamous cell carcinoma of the head and neck. Oral Oncol 51: 291-298, 2015.

26. Kozaki K, Imoto I, Pimkhaokham A, Hasegawa S, Tsuda H, Omura $\mathrm{K}$ and Inazawa $\mathrm{J}$ : PIK3CA mutation is an oncogenic aberration at advanced stages of oral squamous cell carcinoma. Cancer Sci 97: 1351-1358, 2006. 